\title{
Mixed Evidence for Interactive Effects of Outgroup Proportions and Intergroup Contact on Racial Bias in the United States
}

\author{
James R. Rae ${ }^{1} \quad$ Allison L. Skinner-Dorkenoo ${ }^{2} \quad$ Anna-Kaisa Reiman $^{3}$ \\ Katharina Schmid ${ }^{4} \quad$ Miles Hewstone $^{5}$ \\ ${ }^{1}$ Seattle, USA \\ ${ }^{2}$ University of Georgia, USA \\ ${ }^{3}$ University at Albany, State University of New York, USA \\ ${ }^{4}$ Universitat Ramon Llull, Esade Business School, Spain \\ ${ }^{5}$ University of Oxford, UK
}

James R. Rae is a Behavioral Scientist at Zillow Group in Seattle, WA, USA.

Allison L. Skinner-Dorkenoo is an assistant professor of psychology at the University of Georgia. Her research examines how prejudice is established, maintained, and facilitated through situational cues in our social environments.

Anna Reiman is an associate professor of psychology, mainly studying social identity processes at the University at Albany, SUNY.

Katharina Schmid is an associate professor of organizational behavior, mainly studying group dynamics and intergroup relations at Universitat Ramon Llull, Esade Business School, Spain. Miles Hewstone is Emeritus Professor of Psychology, mainly studying intergroup contact and the reduction of prejudice, Oxford University, UK. 


\section{Author Note}

Please address correspondence regarding this research to James R. Rae. Email: james.richard.rae@gmail.com.

\section{Acknowledgments}

The authors thank Kevin King for assistance with statistical analyses and Kristina Olson, Sapna Cheryan, Tony Greenwald, and members of the Social Cognitive Development lab at the University of Washington for comments on an earlier draft of this manuscript.

Word count: 4,989 (excluding tables, figures, references, and the title page but including the abstract) 


\begin{abstract}
Dominant majority-group members living in areas with larger proportions of outgroup members tend to express more ingroup bias. However, prior research has rarely considered this in tandem with the bias-reducing effects of intergroup contact or tested whether outgroup proportions have similar effects for oppressed minority-group members. In two preregistered studies, we tested whether contact moderates the association between outgroup proportions and ingroup bias among White and Black Americans (total $N>75,000$ ). As hypothesized, more Black residents in an area predicted greater explicit (but not implicit) ingroup bias among White respondents who reported low (but not high) contact with Black people. By contrast, more White residents in an area predicted lower explicit (but not implicit) ingroup bias among Black respondents regardless of intergroup contact with White people. We qualify previous findings by demonstrating that the association between outgroup proportions and ingroup bias depends on one's group membership and level of intergroup contact.
\end{abstract}

Keywords: intergroup contact, conflict theory, intergroup relations, implicit bias, Implicit Association Test 


\section{Mixed Evidence for Interactive Effects of Outgroup Proportions and Intergroup Contact on Racial Bias in the United States}

Previous work provides a pessimistic outlook for how exposure to racial diversity may affect racial bias. For example, living in areas with larger proportions of outgroup members predicts greater ingroup bias among White U.S. residents (e.g., Taylor, 1998). But do outgroup proportions impact ingroup bias similarly for everyone? Leveraging large samples of White and Black U.S. respondents who completed both implicit and explicit bias measures, we examined whether contact with outgroups - perhaps the best-known bias-reduction tool (Brown \& Hewstone, 2005) — buffers the association between larger outgroup proportions and heightened ingroup bias, and whether outgroup proportions have similar effects for White and Black respondents.

Conflict theory posits that larger minority proportions threaten dominant majoritygroups' status and power, inciting ingroup bias among majority-group members (Blalock, 1967). Indeed, U.S.-based research suggests that greater proportions of oppressed minority-group members predict higher explicit ingroup bias among dominant majority-group members (Fossett \& Kiecolt, 1989; Quillian, 1996; Taylor, 1998). Parallel results exist for measures of implicit bias (Rae et al., 2015) — an important finding, given that implicit and explicit measures both predict intergroup behavior (Greenwald et al., 2009; Kurdi et al., 2019; cf. Oswald et al., 2013). Implicit bias also predicts contextual-level outcomes such as health disparities across U.S. counties (Orchard \& Price, 2017), racial disparities in police use of force in the U.S. (Hehman et al., 2018), and country-level gender disparities in $8^{\text {th }}$ grade STEM achievement (Nosek et al., 2009). 
Previous work has found that higher outgroup proportions predict greater ingroup bias at larger geographical units (e.g., U.S. states), whereas at smaller geographical units (e.g., neighborhoods) they predict lesser ingroup bias (Oliver \& Wong, 2003; Rae et al., 2015; Wagner et al. 2006). Here, we test whether intergroup contact moderates this association. Positive contact with outgroup members reliably reduces explicit bias (Allport, 1954; Brown \& Hewstone, 2005; Pettigrew \& Tropp, 2006) and may also predict lower implicit bias (Shook \& Fazio, 2008). Although the contact-bias relation can be bidirectional-with greater contact reducing bias and individuals with more positive intergroup attitudes seeking out more contactlongitudinal research supports the conceptualization of contact as an antecedent of bias (Binder et al., 2009; Levin et al., 2003). In the present work, we treated contact as a moderator of the impact of outgroup proportions on bias. We propose that whereas outgroup proportions may predict greater ingroup bias among people experiencing little intergroup contact, people experiencing more contact may be buffered against this outcome.

Living in areas with more outgroup representation may be threatening, especially for dominant majority-group members concerned about maintaining high societal status (Craig \& Richeson, 2014, 2017; Danbold \& Huo, 2015; Devos et al., 2021). However, having more outgroup members in one's environment also provides more opportunities for intergroup contact (Schmid et al., 2014; Stein et al., 2000). Positive interactions with outgroup members can lead them to be recategorized as members of a common ingroup (e.g., neighborhood community), which can reduce intergroup bias by redirecting ingroup favoritism toward those formerly categorized as outgroup members (Gaertner et al., 2016).

The limited research examining interactive effects of outgroup proportions and intergroup contact has had mixed findings. In New Zealand contact predicted warmth toward outgroup 
members only among minority-group members living in areas with low proportions of outgroup members (Barlow et al., 2013). However, other studies have found little evidence of interactive effects of contact and outgroup proportions in data from four European countries and South Africa (Schmid et al., 2017). However, it is critical to note that outgroup proportions were not directly related to outgroup evaluations in any of these studies. This pattern differs from the U.S. context, with its long history of slavery and racial oppression (Kendi, 2016), where larger outgroup proportions reliably predict greater ingroup bias among White residents (Quillian, 1996; Rae et al., 2015; Taylor, 1998). Thus, we sought to determine whether outgroup proportions and intergroup contact jointly predict ingroup bias in a societal context in which outgroup proportions do predict ingroup bias - the U.S.

Accordingly, in an initial preregistered test (Study 1) and a preregistered replication (Study 2), we investigated whether contact moderates the association between outgroup proportions and implicit and explicit racial bias in large samples of Black and White U.S. respondents. We tested whether larger outgroup proportions predict greater racial bias among respondents with low, but not high, intergroup contact (i.e., the buffering hypothesis). Our approach makes several contributions. First, we examine the buffering hypothesis in samples from the U.S., a context in which larger outgroup proportions reliably predict greater ingroup bias (among White residents). Second, we provide the first test of whether intergroup contact interacts with outgroup proportions to predict both explicit and implicit bias. Third, we index outgroup proportions at multiple levels, given that the unit of analysis (states vs. counties) may moderate the association between outgroup proportions and ingroup bias (e.g., Wagner et al., 2006). Previous tests of the buffering hypothesis have not considered outgroup proportions at multiple levels. Fourth, we test the impact of dominant majority-group proportions on oppressed 
minority-group members' ingroup bias, which has rarely been assessed but is necessary for a complete picture of intergroup relations (Shelton, 2000). We made no a priori predictions regarding differences between Black and White respondents. However, membership in a dominant (vs. oppressed) group can alter the psychological impact of outgroup exposure (Danbold \& Unzueta, 2020) and contact (Tropp \& Pettigrew, 2005). Given the history of racial oppression and longstanding notions of White superiority in the U.S., exposure to and contact with one another plausibly impact Black and White U.S. residents in markedly different ways.

\section{Method}

\section{Preregistration}

We preregistered our samples, planned analyses, and hypotheses, which are available along with data and analysis scripts on the Open Science Framework (Study 1; Study 2). We made some deviations from our analysis plan, especially for Study 1. For example, we preregistered that we would examine effects of outgroup proportions at the county level, whereas we eventually examined these effects at the state level as well. All deviations from the preregistration for Study 1 are documented and justified in Supplemental Materials, and the results of our preregistration for Study 1 are reported in Supplemental Materials ${ }^{1}$ (Tables S1-S4). Considering these deviations, the results of Study 1 might be considered exploratory (DeHaven, 2017).

\section{Respondents}

Respondents were drawn from a large online sample collected by Project Implicit (PI; Xu et al., 2014), an educational outreach organization that provides a "virtual laboratory" in which

\footnotetext{
${ }^{1} \mathrm{We}$ do not directly compare the results of our preregistered analyses and those reported in the main text because our preregistered inference criterion (BIC) differs from the criteria we ultimately used ( $p$-values), precluding straightforward comparisons.
} 
people can complete various versions of an implicit bias measure-the Implicit Association Test (IAT; Greenwald et al., 1998) — along with corresponding explicit measures (Project Implicit, n.d.). Respondents in Study 1 completed the Race Implicit Association Test (IAT; Greenwald et al., 1998) between February 2, 2015 (when items measuring intergroup contact were introduced to the battery of self-report items) and December 31, 2015. After we analyzed data from Study 1, data from respondents who completed the same measures in 2016 became available. Thus, Study 2 consists of data from respondents who completed the Race IAT between January 1 and September 26, 2016 (when measures of intergroup contact were rotated off the battery of selfreport items, as happens periodically) and serves as a preregistered replication of Study 1 . We only analyzed data from respondents who completed the intergroup contact items, identified as White or Black (the focal groups on the Race IAT), completed no more than $10 \%$ of IAT trials in less than 300 milliseconds (a standard exclusion criterion; Greenwald et al., 2003), resided in the U.S., and self-reported their state (including the District of Columbia) and county of residence. These procedures yielded final samples of $N=39,495$ (Study 1) and N=35,740 (Study 2). Means of measures and respondents' demographic characteristics are presented in Table 1.

\section{Measures}

\section{Implicit Racial Bias}

The IAT is a reaction time task that indexes associations between pairs of target and attribute concepts (Greenwald et al., 1998, 2003). The Race IAT indexes the strength of association between the target concepts "European American" and "African American" and the attribute concepts "Good" and "Bad." Respondents use two computer keys to rapidly classify European American and African American faces and "Good" (e.g., joy) and "Bad" (e.g., evil) words. In one critical condition, "European American" and "Good" stimuli are classified with 
one response key and "African American" and "Bad" stimuli with another response key. In the other critical condition, "African American" and "Good" and "European American" and "Bad," respectively, are paired with the same response key. Condition order is counterbalanced across respondents. Respondents who classified stimuli more quickly when European American faces and "Good" words shared a response key, relative to when European American faces and "Bad" words shared a response key, are taken to hold a pro-White/anti-Black bias (vice versa for respondents demonstrating the opposite pattern). We used the standard IAT scoring algorithm (Greenwald et al., 2003), which yields a summary score (a $D$-score; ranging from -2 to +2 ). We computed $D$-scores so that higher values indicated more implicit ingroup-favoring bias (proWhite bias for White respondents and pro-Black bias for Black respondents).

\section{Explicit Racial Bias}

A single item assessed explicit racial bias by indexing liking for White (vs. Black) people on a scale ranging from 1 (I strongly prefer African Americans to European Americans) to 7 (I strongly prefer European Americans to African Americans). We centered scores at four (no bias) and coded responses so that higher scores reflected higher ingroup-favoring bias (pro-White bias for White respondents and pro-Black bias for Black respondents).

\section{Intergroup Contact}

Selecting as many as applicable from a list of racial/ethnic groups (Asian, Black, Hispanic, Native American, Pacific Islander, and White), respondents indicated whether they have or have had family members (three items: I have a parent who is..., I have a close family member of my own generation who is..., I have a close family member younger than my generation who is...), friends (two items: I had a strong childhood friendship with a person who is..., I have had [or now have] a strong post-childhood friendship with a person who is ...), or 
romantic partners (one item: I have had [or now have] a romantic relationship with a person who is ...) from each group. We created a count variable based on the number of items for which respondents selected "Black" or "White." Thus, Black respondents would score a "1" for all items in which they indicated having a close relationship with a White person (and vice versa for White respondents). Scores ranged from 0 to 6, with higher scores indicating more outgroup contact.

\section{Outgroup Proportions}

The percentage of Black (White) residents indexed outgroup proportions for White (Black) respondents (see Table 1 for state- and county-level estimates). Focusing exclusively on Black/White proportions allowed us to map outgroup proportions onto our outcome measures of relative Black-White implicit and explicit biases. Estimates were obtained from the American Community Survey (ACS), disseminated yearly by the U.S. Census Bureau. We used 5-year averages of data collected between 2010 and 2014 to balance using ACS data that most accurately characterized respondents' states and counties when they completed the study and minimizing data loss due to an inability to provide exposure estimates for respondents (given that areas of $\leq 20,000$ residents are only eligible for 5-year ACS estimates).

\section{Demographics and Contextual Variables}

Respondents reported their racial identity, age, gender identity (recoded as $-0.5=$ female; $0.5=$ male), political orientation (recoded as $-3=$ strongly liberal $;+3=$ strongly conservative), and education level (see Supplemental Material for detail). Student and non-student respondents reported their education level on different response scales. To make responses between these groups comparable, we put responses on a percentage metric (Cohen et al., 1999). Using 2014 ACS 5-year estimates, we obtained state-level and county-level measures of average education 
level, median household income, population density ${ }^{2}$, proportion of residents who are not U.S. citizens, and degree of economic inequality (the Gini coefficient). We obtained voting returns from the 2012 Presidential Election to approximate political orientation at both state and county levels.

\section{Procedure}

Respondents entered the PI website and self-selected to complete the Race IAT. The IAT, explicit bias measures, and demographics were presented in a randomized order.

\section{Analytic Strategy}

Intraclass correlations for implicit and explicit bias scores were small (range=.000-.024), indicating that shared variability among residents within a specific state or county was low (02.4\%). Nonetheless, we used a multilevel modeling approach given the hierarchical structure of the data (Nezlek, 2008): Respondents (Level 1) were nested within counties (Level 2) and states (Level 3). A large number of Level 3 units is necessary for achieving adequate statistical power (Snijders, 2005). Simulation studies suggest that having 50 observations at the highest level allows for unbiased estimates of fixed effects and standard errors (Maas \& Hox, 2005), which is approximately the number of states sampled in our studies (see Table 1). Thus, although our sample sizes were dictated by the amount of data available, we met recommendations for adequate power. Analyses were carried out using the lme4 (Bates et al., 2015) and lmerTest (Kuznetsova et al., 2014) packages in R (R Core Team, 2014).

In hierarchically nested data, the outcome variable can be associated with the predictor variable at multiple levels of analysis (Enders \& Tofighi, 2007). For example, the total association between ingroup bias and intergroup contact reflects person-specific (i.e., effects of a

\footnotetext{
${ }^{2}$ Population density estimates were not available for 2014, so we used estimates from 2015.
} 
person's intergroup contact), county-specific (i.e., effects of a county's average level of intergroup contact), and state-specific (i.e., effects of a state's average level of intergroup contact) components (for an example, see Christ et al., 2014). Centering predictor variables is useful for disentangling associations within and between levels of analysis (Raudenbush \& Bryk, 2002). Given that predictors at the highest level of analysis can only be grand-mean centered, we centered state-level outgroup proportions from the mean across all states. However, variation in predictors at lower levels of analysis can be isolated via centering within clusters (Brincks et al., 2017; Enders \& Tofighi, 2007). Thus, to isolate person-specific variation in intergroup contact and county-specific variation in outgroup proportions, we centered intergroup contact at the county-level mean and county-level outgroup proportions at the state outgroup proportion as indexed by Census data. ${ }^{3}$ Centering Level 1 predictors within clusters, as we do here, is recommended when investigating cross-level interactions (Enders \& Tofighi, 2007; see also Bauer \& Curran, 2005).

For each analysis, we fit a model estimating fixed effects for intergroup contact, countylevel and state-level outgroup proportions, and, central to testing the buffering hypothesis, the two-way interactions between intergroup contact and county-level and state-level outgroup proportions. We also included random intercepts for county and state, and, following the recommendations of Heisig and Schaeffer (2019) for investigating cross-level interactions, our models allowed the slope for contact to vary across counties and states (i.e., a random slope). ${ }^{4}$ To test the robustness of our results, we re-examined our model after introducing demographic (age, gender identity, education level, and political orientation) and contextual (education level,

\footnotetext{
${ }^{3}$ As preregistered, we examined the interactive effects of contact at the individual level. However, exploratory analyses examining parallel effects for contextual-level contact (see Christ et al., 2014) are available in Supplemental Materials (Tables S13-S16).

${ }^{4}$ We thank an anonymous reviewer for this suggestion.
} 
median household income, population density, proportion of residents who are not U.S. citizens, economic inequality, and political orientation) control variables (variables at Levels 1 and 2 were centered within clusters; variables at Level 3 were grand-mean centered). As in previous work (Rae et al., 2015; Schmid et al., 2014), given the dramatic difference in sample sizes (which can exacerbate homogeneity of variance violations), we analyzed results for White and Black respondents separately. ${ }^{5}$

\footnotetext{
${ }^{5}$ See the Supplemental Material (Tables S9-S12 and Figures S5-S7) for exploratory analyses conducted on combined samples of White and Black respondents.
} 
Table 1. Individual and demographic characteristics among respondents for whom any data are reported in Study 1 (data collected in 2015) and Study 2 (data collected in 2016).

\begin{tabular}{|c|c|c|c|c|}
\hline \multirow[b]{2}{*}{ Variable } & \multicolumn{2}{|c|}{ Study 1} & \multicolumn{2}{|c|}{ Study 2} \\
\hline & $\begin{array}{l}\text { White Respondents } \\
\quad(N=33,890)\end{array}$ & $\begin{array}{l}\text { Black Respondents } \\
\quad(N=5,603)\end{array}$ & $\begin{array}{l}\text { White Respondents } \\
\qquad(N=30,890)\end{array}$ & $\begin{array}{c}\text { Black Respondents } \\
\quad(N=4,924)\end{array}$ \\
\hline \multicolumn{5}{|l|}{ Level 1: Person } \\
\hline Implicit bias, mean $(S D)$ & $0.36(0.42)$ & $0.05(0.44)$ & $0.33(0.42)$ & $0.08(0.45)$ \\
\hline Explicit bias, mean $(S D)$ & $0.45(0.83)$ & $0.80(1.19)$ & $0.41(0.79)$ & $0.88(1.19)$ \\
\hline Intergroup contact $(S D)$ & $1.33(1.20)$ & $2.12(1.60)$ & $1.38(1.21)$ & $2.17(1.62)$ \\
\hline Percentage male & $38.4 \%$ & $33.4 \%$ & $38.6 \%$ & $34.1 \%$ \\
\hline Age in years, mean $(S D)$ & $29.0(12.9)$ & $28.2(12.0)$ & $30.2(13.8)$ & $28.2(12.3)$ \\
\hline Political conservatism $(S D)$ & $-0.69(1.74)$ & $-0.83(1.41)$ & $-0.74(1.79)$ & $-0.92(1.42)$ \\
\hline Education in percentage, mean $(S D)$ & $71.9 \%(22.2 \%)$ & $71.4 \%(21.8 \%)$ & $75.3 \%(21.8 \%)$ & $74.0 \%(21.4 \%)$ \\
\hline \multicolumn{5}{|l|}{ Level 2: County } \\
\hline Outgroup proportions, mean $(S D)$ & $12.3 \%(12.5 \%)$ & $63.3 \%(16.4 \%)$ & $12.7 \%(12.7 \%)$ & $63.3 \%(16.3 \%)$ \\
\hline Number of counties represented & 1,954 & 726 & 1,887 & 656 \\
\hline \multicolumn{5}{|l|}{ Level 3: State } \\
\hline Outgroup proportions, mean $(S D)$ & $12.0 \%(8.51 \%)$ & $71.5 \%(9.66 \%)$ & $12.2 \%(8.30 \%)$ & $71.5 \%(9.55 \%)$ \\
\hline Number of states represented & 51 & 48 & 45 & 43 \\
\hline
\end{tabular}

Note. Level indicates the unit at which predictors were measured. Higher implicit and explicit bias scores reflect greater ingroup favoritism. Washington DC was treated as a state in our analyses. Intergroup contact was measured on a 0-6 scale. Political conservativism was measured on a -3 to +3 scale. 


\section{Results}

\section{Descriptive Statistics}

Means and standard deviations for all key measures are presented in Table 1. Replicating previous work (Nosek et al., 2007), White (vs. Black) respondents had stronger implicit ingroup favoritism, whereas Black (vs. White) respondents had stronger explicit ingroup favoritism. Moreover, contact scores were low-White respondents, on average, tended to report roughly one type of contact experience (out of six possible types of experiences), whereas Black respondents reported closer to two types of contact experiences. Table 1 also shows that White respondents tended to live in states and counties with relatively few outgroup members (i.e., Black residents), and Black respondents tended to live in states and counties composed primarily of outgroup members (i.e., White residents). Figure 1 further demonstrates this fact by showing the distribution of outgroup proportions for respondents in Studies 1 and 2.

Figure 2 presents zero-order correlations among variables in Table 1. There are three notable findings: First, consistent with contact theory, contact was correlated with lower implicit (White 2015: $r=-.12$; White 2016: $r=-.11$; Black 2015: $r=-.09$; Black 2016: $r=-.06$ ) and, especially, explicit (White 2015: $r=-.25$; White 2016: $r=-.26$; Black 2015: $r=-.24$; Black 2016: $r=-.22)$ ingroup bias. Second, implicit and explicit biases were only weakly — if at all—related to county- and state-level outgroup proportions, with $r$ 's ranging in absolute magnitude from .00 to .08 (see Table 2). Third, outgroup proportions were differentially related to implicit and explicit bias scores for White and Black respondents. Living in areas with higher proportions of outgroup members predicted greater implicit and explicit ingroup bias for White respondents and lower implicit and explicit ingroup bias for Black respondents (see Table 2). 


\section{Outgroup proportions for White and Black respondents}

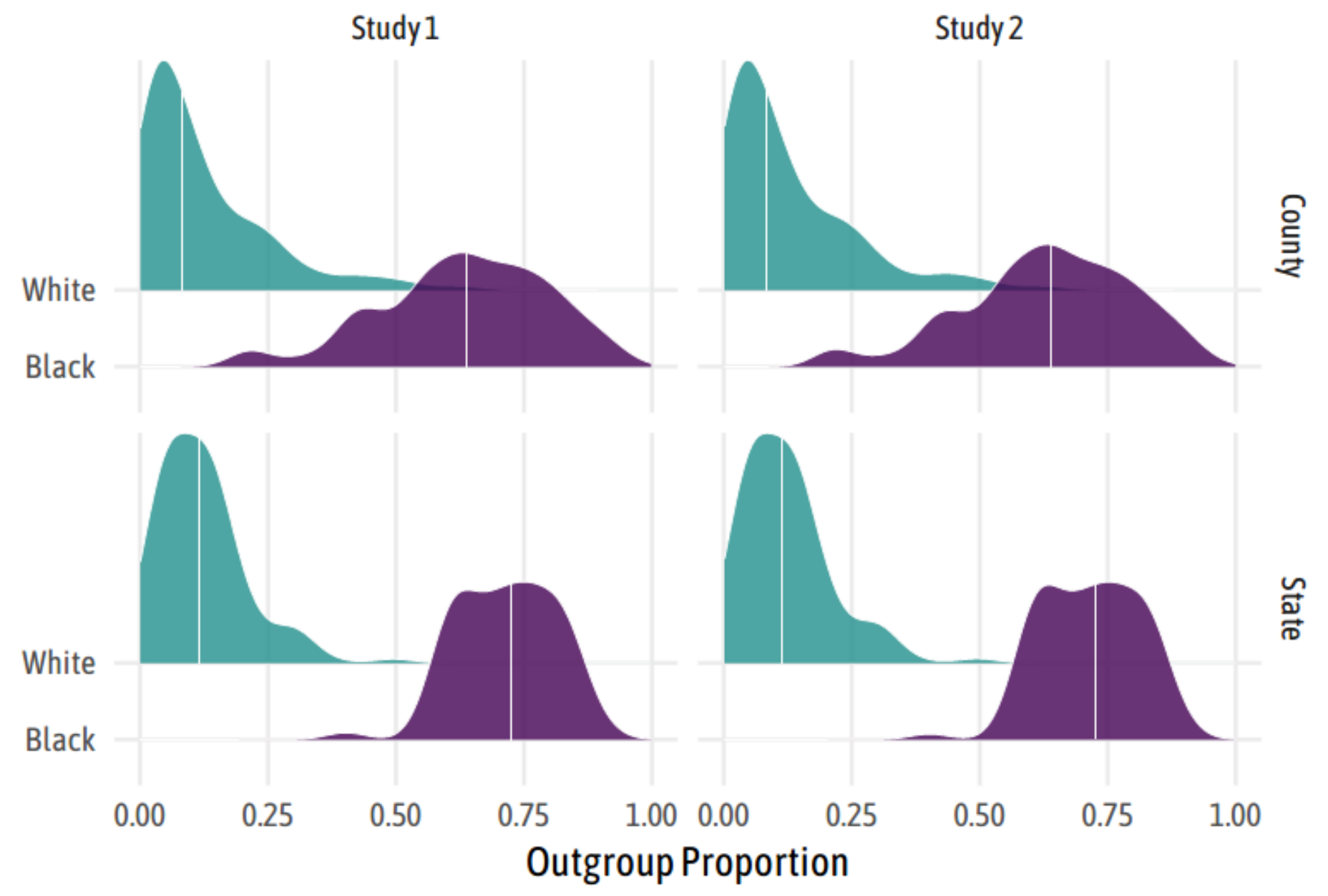

Figure 1. State and county outgroup proportions for White and Black residents for Study 1 and Study 2. The white vertical line shows the median for each distribution. 

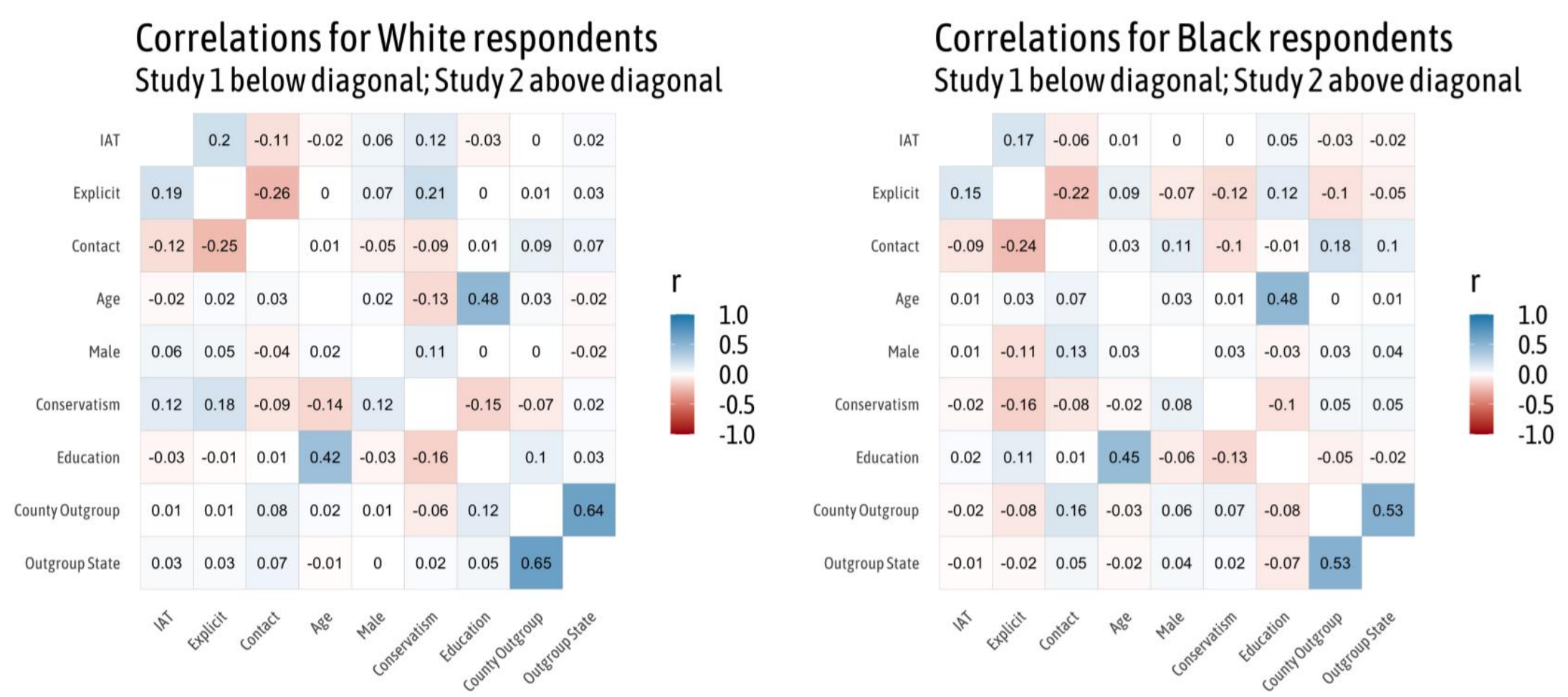

Figure 2. Zero-order correlations among variables measured at the person-level, as well as county- and state-level outgroup proportions, for White respondents (left panel) and Black respondents (right panel). Correlations from Study 1 are below the diagonal and correlations for Study 2 are above the diagonal. 


\section{Multilevel Modeling Results: White Respondents}

Table 2 shows multilevel modeling results for White respondents' implicit bias. Across both studies (with and without covariates in the model), there was a main effect of contact, such that White respondents who reported more types of contact with Black people tended to have lower implicit ingroup bias. However, county- and state-level outgroup proportions were not consistently related to White respondents' implicit ingroup bias. Thus, any association between outgroup proportions and White respondents' implicit ingroup bias was not robust, such that it either depended on including covariates in the model or was not reliable once covariates were included the model. Similarly, we observed no reliable evidence for interactions between contact and outgroup proportions (state-level or county-level) on White respondents' implicit ingroup bias.

Table 3 shows highly consistent results across studies on White respondents' explicit ingroup bias. First, having more types of contact with Black people was associated with lower explicit ingroup bias. Second, White respondents living in states with more Black residents tended to express greater explicit ingroup favoritism. Third, we observed reliable interactions between contact and state-level outgroup proportions on White respondents' explicit ingroup bias. We conducted multilevel simple slopes analyses (Preacher et al., 2006) to interpret these interactions. As shown in Figure 3, the association between state-level outgroup proportions and explicit ingroup bias was stronger for White respondents with contact below the county mean (recall that contact was centered within counties) and weaker (in fact, statistically nonsignificant) for White respondents above the county mean. 
Table 2. Associations of intergroup contact, outgroup proportions, and intergroup contact $\times$ outgroup proportions with White respondents' implicit ingroup bias in Studies 1 and 2.

\begin{tabular}{|c|c|c|c|c|c|c|c|c|c|c|c|c|}
\hline \multirow[b]{3}{*}{ Predictors } & \multicolumn{6}{|c|}{ Study 1} & \multicolumn{6}{|c|}{ Study 2} \\
\hline & \multicolumn{3}{|c|}{ No Covariate Model } & \multicolumn{3}{|c|}{ Covariate Model } & \multicolumn{3}{|c|}{ No Covariate Model } & \multicolumn{3}{|c|}{ Covariate Model } \\
\hline & Estimates & $S E$ & $p$ & Estimates & $S E$ & $p$ & Estimates & $S E$ & $p$ & Estimates & $S E$ & $p$ \\
\hline Intercept & 0.36 & 0.00 & $<.001$ & 0.36 & 0.01 & $<.001$ & 0.34 & 0.00 & $<.001$ & 0.34 & 0.01 & $<.001$ \\
\hline Contact (L1) & -0.04 & 0.00 & $<.001$ & -0.04 & 0.00 & $<.001$ & -0.04 & 0.00 & $<.001$ & -0.04 & 0.00 & $<.001$ \\
\hline Percent Outgroup (L2) & -0.06 & 0.03 & .040 & -0.04 & 0.04 & .337 & -0.07 & 0.03 & .011 & -0.02 & 0.04 & .685 \\
\hline Percent Outgroup (L3) & 0.08 & 0.05 & .077 & 0.11 & 0.07 & .094 & 0.09 & 0.05 & .043 & 0.13 & 0.07 & .052 \\
\hline Contact $\times$ Percent Outgroup (L2) & -0.04 & 0.02 & .060 & -0.05 & 0.02 & .038 & -0.03 & 0.02 & .118 & -0.03 & 0.02 & .209 \\
\hline Contact $\times$ Percent Outgroup (L3) & -0.02 & 0.02 & .494 & -0.01 & 0.03 & .700 & -0.03 & 0.03 & .271 & -0.01 & 0.03 & .715 \\
\hline Male (L1) & & & & 0.04 & 0.01 & $<.001$ & & & & 0.04 & 0.01 & $<.001$ \\
\hline Political Conservatism (L1) & & & & 0.02 & 0.00 & $<.001$ & & & & 0.02 & 0.00 & $<.001$ \\
\hline Age (L1) & & & & 0.00 & 0.00 & .620 & & & & 0.00 & 0.00 & .961 \\
\hline Education level (L1) & & & & 0.00 & 0.00 & .046 & & & & 0.00 & 0.00 & .021 \\
\hline Percent U.S. Citizens (L2) & & & & 0.03 & 0.12 & .816 & & & & 0.10 & 0.11 & .364 \\
\hline Percent Bachelors or Greater (L2) & & & & -0.43 & 0.10 & $<.001$ & & & & -0.24 & 0.09 & .010 \\
\hline Percent Democrat 2012 (L2) & & & & 0.00 & 0.00 & .856 & & & & 0.00 & 0.00 & .141 \\
\hline Population Density (L2) & & & & 0.00 & 0.00 & .275 & & & & 0.00 & 0.00 & .769 \\
\hline Median Income (L2) & & & & 0.00 & 0.00 & $<.001$ & & & & 0.00 & 0.00 & .002 \\
\hline Gini Coefficient (L2) & & & & 0.47 & 0.18 & .008 & & & & 0.26 & 0.17 & .117 \\
\hline Percent U.S. Citizens (L3) & & & & 0.00 & 0.24 & .998 & & & & -0.08 & 0.24 & .750 \\
\hline Percent Bachelors or Greater (L3) & & & & -0.15 & 0.33 & .653 & & & & -0.19 & 0.33 & .568 \\
\hline Percent Democrat 2012 (L3) & & & & 0.00 & 0.00 & .267 & & & & 0.00 & 0.00 & .124 \\
\hline Population Density (L3) & & & & 0.00 & 0.00 & .090 & & & & 0.00 & 0.00 & .741 \\
\hline Median Income (L3) & & & & 0.00 & 0.00 & .786 & & & & 0.00 & 0.00 & .251 \\
\hline Gini Coefficient (L3) & & & & -0.02 & 0.51 & .964 & & & & -0.32 & 0.52 & .538 \\
\hline
\end{tabular}

Note. The level at which predictors were measured is shown in parentheses: L1=Person, L2=County, L3=State. Estimates are unstandardized and standard errors are shown in parentheses. 
Table 3. Associations of intergroup contact, outgroup proportions, and intergroup contact $\times$ outgroup proportions with White respondents' explicit ingroup bias in Studies 1 and 2.

\begin{tabular}{|c|c|c|c|c|c|c|c|c|c|c|c|c|}
\hline \multirow[b]{3}{*}{ Predictors } & \multicolumn{6}{|c|}{ Study 1} & \multicolumn{6}{|c|}{ Study 2} \\
\hline & \multicolumn{3}{|c|}{ No Covariate Model } & \multicolumn{3}{|c|}{ Covariate Model } & \multicolumn{3}{|c|}{ No Covariate Model } & \multicolumn{3}{|c|}{ Covariate Model } \\
\hline & Estimates & $S E$ & $p$ & Estimates & $S E$ & $p$ & Estimates & $S E$ & $p$ & Estimates & $S E$ & $p$ \\
\hline Intercept & 0.45 & 0.01 & $<.001$ & 0.45 & 0.01 & $<.001$ & 0.42 & 0.01 & $<.001$ & 0.41 & 0.01 & $<.001$ \\
\hline Contact (L1) & -0.18 & 0.00 & $<.001$ & -0.17 & 0.00 & $<.001$ & -0.16 & 0.00 & $<.001$ & -0.15 & 0.01 & $<.001$ \\
\hline Percent Outgroup (L2) & -0.11 & 0.06 & .065 & 0.04 & 0.08 & .604 & -0.11 & 0.06 & .056 & -0.02 & 0.08 & .842 \\
\hline Percent Outgroup (L3) & 0.34 & 0.09 & $<.001$ & 0.50 & 0.13 & $<.001$ & 0.34 & 0.10 & .001 & 0.51 & 0.14 & $<.001$ \\
\hline Contact $\times$ Percent Outgroup (L2) & -0.06 & 0.04 & .178 & -0.10 & 0.05 & .035 & -0.05 & 0.04 & .171 & 0.00 & 0.04 & .910 \\
\hline Contact $\times$ Percent Outgroup (L3) & -0.31 & 0.05 & $<.001$ & -0.30 & 0.06 & $<.001$ & -0.18 & 0.05 & .001 & -0.15 & 0.06 & .009 \\
\hline Male (L1) & & & & 0.06 & 0.01 & $<.001$ & & & & 0.04 & 0.01 & $<.001$ \\
\hline Political Conservatism (L1) & & & & 0.09 & 0.00 & $<.001$ & & & & 0.07 & 0.00 & $<.001$ \\
\hline Age (L1) & & & & 0.00 & 0.00 & .003 & & & & 0.00 & 0.00 & $<.001$ \\
\hline Education level (L1) & & & & 0.00 & 0.00 & .004 & & & & 0.00 & 0.00 & .270 \\
\hline Percent U.S. Citizens (L2) & & & & 0.20 & 0.23 & .390 & & & & 0.20 & 0.22 & .369 \\
\hline Percent Bachelors or Greater (L2) & & & & -0.55 & 0.20 & .006 & & & & -0.61 & 0.19 & .002 \\
\hline Percent Democrat 2012 (L2) & & & & 0.00 & 0.00 & .057 & & & & 0.00 & 0.00 & .062 \\
\hline Population Density (L2) & & & & 0.00 & 0.00 & .525 & & & & 0.00 & 0.00 & .431 \\
\hline Median Income (L2) & & & & 0.00 & 0.00 & .001 & & & & 0.00 & 0.00 & .002 \\
\hline Gini Coefficient (L2) & & & & 0.42 & 0.35 & .234 & & & & 0.49 & 0.34 & .149 \\
\hline Percent U.S. Citizens (L3) & & & & 0.13 & 0.45 & .775 & & & & 0.09 & 0.53 & .861 \\
\hline Percent Bachelors or Greater (L3) & & & & -0.17 & 0.62 & .788 & & & & -0.50 & 0.70 & .473 \\
\hline Percent Democrat 2012 (L3) & & & & 0.00 & 0.00 & .625 & & & & 0.00 & 0.00 & .831 \\
\hline Population Density (L3) & & & & 0.00 & 0.00 & .105 & & & & 0.00 & 0.00 & .145 \\
\hline Median Income (L3) & & & & 0.00 & 0.00 & .624 & & & & 0.00 & 0.00 & .994 \\
\hline Gini Coefficient (L3) & & & & -0.70 & 0.97 & .469 & & & & -0.83 & 1.11 & .454 \\
\hline
\end{tabular}

Note. The level at which predictors were measured is shown in parentheses: L1=Person, L2=County, L3=State. Estimates are unstandardized and standard errors are shown in parentheses. 

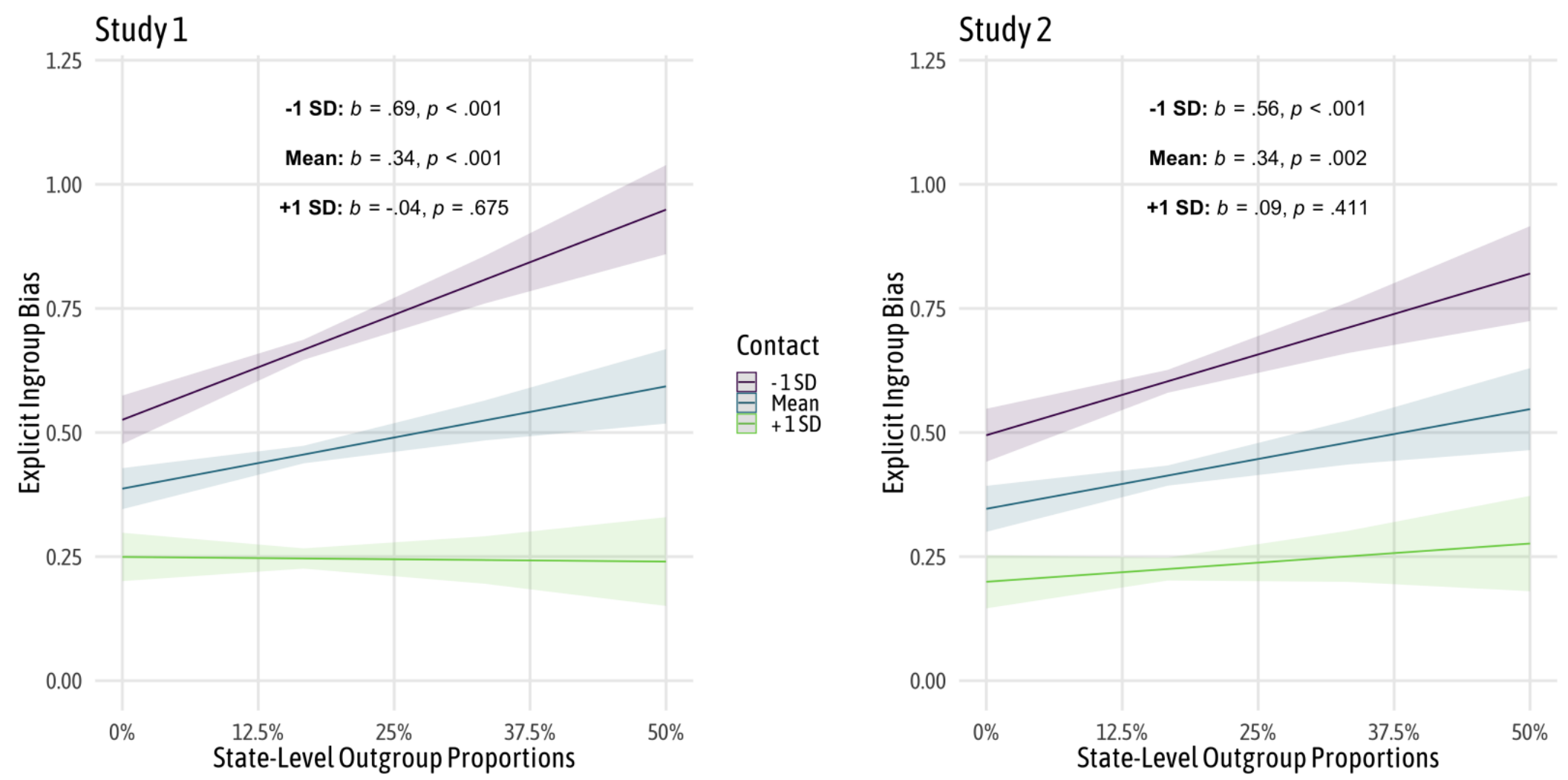

Contact

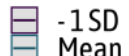

Mean
+1 SD

Figure 3. Intergroup contact interacts with state-level outgroup proportions to predict White respondents' explicit ingroup bias in Study 1 (left panel) and Study 2 (right panel). Simple slopes are plotted with 95\% confidence intervals (shaded regions) for respondents at $\pm 1 S D$, as well as the county mean (given that contact scores were centered within counties). 


\section{Multilevel Modelling Results: Black Respondents}

As shown in Table 4, having more types of contact with White people was associated with lower implicit ingroup bias among Black respondents. In fact, contact was the only reliable predictor (in both studies, with and without covariates) of Black respondents' implicit ingroup bias. In no model did we find evidence that outgroup proportions (county- or state-level) predicted Black respondents' implicit ingroup bias, nor did we observe evidence for interactive effects of contact and outgroup proportions on Black respondents' implicit ingroup bias.

Contact also predicted lower levels of explicit ingroup bias among Black respondents (see Table 5). Moreover, we observed reliable evidence of a main effect of county-level outgroup proportions, but this effect was in the opposite direction of the outgroup proportions effect for White respondents. Whereas White respondents living in states with more Black residents tended to express greater explicit ingroup bias, Black respondents living in counties with more White residents tended to express lesser explicit ingroup bias. Finally, we did not observe reliable evidence for either a main effect of state-level outgroup proportions, or interactive effects between contact and outgroup proportions on Black respondents' explicit ingroup bias (see Table $5) .^{6}$

\footnotetext{
${ }^{6}$ In Supplemental Materials, we report reviewer-requested analyses in which we combined White and Black respondents to examine the Race $\times$ Contact $\times$ State-Level Outgroup Proportions interaction. Results are largely consistent with those reported in the main text. The interactive effects between contact and outgroup proportions did not vary reliably by respondent race in Study 2, but consistent with results reported here, pooled analyses across both studies indicated that contact only moderated the effect of outgroup proportions among White respondents.
} 
Table 4. Associations of intergroup contact, outgroup proportions, and intergroup contact $\times$ outgroup proportions with Black respondents' implicit ingroup bias in Studies 1 and 2.

\begin{tabular}{|c|c|c|c|c|c|c|c|c|c|c|c|c|}
\hline \multirow[b]{3}{*}{ Predictors } & \multicolumn{6}{|c|}{ Study 1} & \multicolumn{6}{|c|}{ Study 2} \\
\hline & \multicolumn{3}{|c|}{ No Covariate Model } & \multicolumn{3}{|c|}{ Covariate Model } & \multicolumn{3}{|c|}{ No Covariate Model } & \multicolumn{3}{|c|}{ Covariate Model } \\
\hline & Estimates & $S E$ & $p$ & Estimates & $S E$ & $p$ & Estimates & $S E$ & $p$ & Estimates & $S E$ & $p$ \\
\hline Intercept & 0.05 & 0.01 & $<.001$ & 0.06 & 0.01 & $<.001$ & 0.07 & 0.01 & $<.001$ & 0.08 & 0.01 & $<.001$ \\
\hline Contact (L1) & -0.02 & 0.00 & .002 & -0.02 & 0.01 & .002 & -0.02 & 0.01 & $<.001$ & -0.03 & 0.01 & $<.001$ \\
\hline Percent Outgroup (L2) & -0.06 & 0.05 & .181 & 0.00 & 0.07 & .965 & -0.08 & 0.05 & .090 & -0.03 & 0.07 & .716 \\
\hline Percent Outgroup (L3) & -0.10 & 0.07 & .145 & -0.10 & 0.13 & .437 & -0.06 & 0.07 & .388 & -0.05 & 0.11 & .685 \\
\hline Contact $\times$ Percent Outgroup (L2) & -0.04 & 0.03 & .173 & -0.03 & 0.04 & .328 & 0.00 & 0.03 & .916 & 0.01 & 0.04 & .802 \\
\hline Contact $\times$ Percent Outgroup (L3) & -0.02 & 0.04 & .552 & -0.01 & 0.05 & .781 & -0.05 & 0.05 & .265 & -0.03 & 0.05 & .522 \\
\hline Male (L1) & & & & 0.02 & 0.02 & .256 & & & & 0.03 & 0.02 & .067 \\
\hline Political Conservatism (L1) & & & & 0.00 & 0.01 & .961 & & & & -0.01 & 0.01 & .205 \\
\hline Age (L1) & & & & 0.00 & 0.00 & .549 & & & & 0.00 & 0.00 & .525 \\
\hline Education level (L1) & & & & 0.00 & 0.00 & .009 & & & & 0.00 & 0.00 & .454 \\
\hline Percent U.S. Citizens (L2) & & & & 0.01 & 0.25 & .952 & & & & 0.00 & 0.23 & .999 \\
\hline Percent Bachelors or Greater (L2) & & & & 0.07 & 0.25 & .781 & & & & -0.18 & 0.25 & .469 \\
\hline Percent Democrat 2012 (L2) & & & & 0.00 & 0.00 & .600 & & & & 0.00 & 0.00 & .983 \\
\hline Population Density (L2) & & & & 0.00 & 0.00 & .445 & & & & 0.00 & 0.00 & .986 \\
\hline Median Income (L2) & & & & 0.00 & 0.00 & .245 & & & & 0.00 & 0.00 & .858 \\
\hline Gini Coefficient (L2) & & & & 0.33 & 0.40 & .416 & & & & 0.45 & 0.39 & .244 \\
\hline Percent U.S. Citizens (L3) & & & & 0.23 & 0.39 & .565 & & & & 0.08 & 0.35 & .816 \\
\hline Percent Bachelors or Greater (L3) & & & & -0.79 & 0.73 & .280 & & & & -0.03 & 0.62 & .962 \\
\hline Percent Democrat 2012 (L3) & & & & 0.00 & 0.00 & .995 & & & & 0.00 & 0.00 & .916 \\
\hline Population Density (L3) & & & & 0.00 & 0.00 & .995 & & & & 0.00 & 0.00 & .400 \\
\hline Median Income (L3) & & & & 0.00 & 0.00 & .244 & & & & 0.00 & 0.00 & .689 \\
\hline Gini Coefficient (L3) & & & & 0.96 & 1.10 & .381 & & & & 0.69 & 1.03 & .503 \\
\hline
\end{tabular}

Note. The level at which predictors were measured is shown in parentheses: L1=Person, L2=County, L3=State. Estimates are unstandardized and standard errors are shown in parentheses. 
Table 5. Associations of intergroup contact, outgroup proportions, and intergroup contact $\times$ outgroup proportions with Black respondents' explicit ingroup bias in Studies 1 and 2.

\begin{tabular}{|c|c|c|c|c|c|c|c|c|c|c|c|c|}
\hline \multirow[b]{3}{*}{ Predictors } & \multicolumn{6}{|c|}{ Study 1} & \multicolumn{6}{|c|}{ Study 2} \\
\hline & \multicolumn{3}{|c|}{ No Covariate Model } & \multicolumn{3}{|c|}{ Covariate Model } & \multicolumn{3}{|c|}{ No Covariate Model } & \multicolumn{3}{|c|}{ Covariate Model } \\
\hline & Estimates & $S E$ & $p$ & Estimates & $S E$ & $p$ & Estimates & $S E$ & $p$ & Estimates & $S E$ & $p$ \\
\hline Intercept & 0.73 & 0.03 & $<.001$ & 0.72 & 0.03 & $<.001$ & 0.80 & 0.02 & $<.001$ & 0.78 & 0.03 & $<.001$ \\
\hline Contact (L1) & -0.17 & 0.02 & $<.001$ & -0.17 & 0.02 & $<.001$ & -0.18 & 0.01 & $<.001$ & -0.18 & 0.01 & $<.001$ \\
\hline Percent Outgroup (L2) & -0.79 & 0.13 & $<.001$ & -0.75 & 0.18 & $<.001$ & -0.78 & 0.15 & $<.001$ & -0.63 & 0.21 & .003 \\
\hline Percent Outgroup (L3) & -0.78 & 0.25 & .002 & -0.09 & 0.32 & .779 & -0.18 & 0.24 & .452 & 0.25 & 0.40 & .532 \\
\hline Contact $\times$ Percent Outgroup (L2) & -0.07 & 0.08 & .401 & -0.01 & 0.09 & .895 & -0.08 & 0.08 & .328 & -0.05 & 0.09 & .610 \\
\hline Contact $\times$ Percent Outgroup (L3) & -0.03 & 0.14 & .845 & 0.10 & 0.15 & .513 & -0.05 & 0.11 & .650 & 0.01 & 0.12 & .959 \\
\hline Male (L1) & & & & -0.13 & 0.04 & .001 & & & & -0.13 & 0.04 & .001 \\
\hline Political Conservatism (L1) & & & & -0.10 & 0.01 & $<.001$ & & & & -0.12 & 0.01 & $<.001$ \\
\hline Age (L1) & & & & 0.01 & 0.00 & .001 & & & & 0.00 & 0.00 & .537 \\
\hline Education level (L1) & & & & 0.00 & 0.00 & $<.001$ & & & & 0.01 & 0.00 & $<.001$ \\
\hline Percent U.S. Citizens (L2) & & & & -1.14 & 0.60 & .058 & & & & -0.59 & 0.69 & .393 \\
\hline Percent Bachelors or Greater (L2) & & & & 1.66 & 0.62 & .007 & & & & 2.19 & 0.71 & .002 \\
\hline Percent Democrat 2012 (L2) & & & & 0.00 & 0.00 & .807 & & & & 0.00 & 0.00 & .602 \\
\hline Population Density (L2) & & & & 0.00 & 0.00 & .123 & & & & 0.00 & 0.00 & .685 \\
\hline Median Income (L2) & & & & 0.00 & 0.00 & .055 & & & & 0.00 & 0.00 & .045 \\
\hline Gini Coefficient (L2) & & & & -0.98 & 0.99 & .319 & & & & -1.22 & 1.13 & .284 \\
\hline Percent U.S. Citizens (L3) & & & & 0.19 & 1.00 & .853 & & & & -0.83 & 1.24 & .506 \\
\hline Percent Bachelors or Greater (L3) & & & & 0.50 & 1.85 & .786 & & & & 0.92 & 2.15 & .669 \\
\hline Percent Democrat 2012 (L3) & & & & 0.01 & 0.00 & .106 & & & & 0.00 & 0.01 & .429 \\
\hline Population Density (L3) & & & & 0.00 & 0.00 & .750 & & & & 0.00 & 0.00 & .685 \\
\hline Median Income (L3) & & & & 0.00 & 0.00 & .764 & & & & 0.00 & 0.00 & .990 \\
\hline Gini Coefficient (L3) & & & & 3.20 & 2.78 & .249 & & & & 1.53 & 3.32 & .645 \\
\hline
\end{tabular}

Note. The level at which predictors were measured is shown in parentheses: L1=Person, L2=County, L3=State. Estimates are unstandardized and standard errors are shown in parentheses. 


\section{Discussion}

The primary objective of the present work was to test the buffering hypothesis - that intergroup contact qualifies the positive association between outgroup proportions and ingroup bias - in a societal context in which outgroup proportions reliably predict ingroup bias. We tested this hypothesis in two large samples of White and Black U.S. respondents. We found robust evidence of outgroup contact predicting lower implicit and explicit ingroup bias among both Black and White respondents. Moreover, results for White respondents' explicit bias supported our preregistered buffering hypothesis. Larger proportions of Black residents in one's state predicted greater explicit ingroup bias among White respondents reporting low (but not high) contact with Black people. This pattern was not observed on the implicit measure, however. Thus, contrasting with previous findings obtained in cultural contexts in which outgroup proportions do not directly predict ingroup bias (Barlow et al., 2013; Schmid et al., 2017), the present findings provide evidence that intergroup contact can buffer the aggravating effect of larger outgroup proportions on ingroup bias. We also examined the impact of dominant majority-group proportions on oppressed minority-group members' ingroup biases, finding that Black U.S. respondents did not show evidence of the buffering hypothesis (consistent with the reported weaker effect of contact among minority-group members; Pettigrew \& Tropp, 2005).

Our findings have implications for the debate about how large outgroup proportions may negatively impact intergroup biases (Taylor, 1998) and social outcomes more generally (Putnam, 2007). Indeed, in the sole instance where we observed that larger outgroup proportions predicted greater intergroup bias (for White respondents' explicit bias), the relation held only for respondents reporting low contact with Black people. Thus, our research shows that larger outgroup proportions and racial diversity may stoke ingroup bias for dominant majority-group 
members with low intergroup contact. Our results have practical implications insofar as they suggest that intergroup contact can buffer against the heightened ingroup bias that may be associated with greater outgroup proportions.

Our work also suggests that the impact of outgroup proportions depends on group status, such that living near outgroup members may predict opposite patterns of ingroup bias for dominant (vs. oppressed) groups. What might explain this divergence? One possibility is that perceived group-based competition for resources might be highest when group boundaries are most salient. If group boundaries are maximally distinct when group sizes are equal, one might expect threat and bias for both groups to be highest as group proportions approach 50:50 (for similar arguments, see Longshore, 1982; Mullen, 1991). To explore this possibility, we plotted average levels of implicit and explicit bias for White and Black respondents against the percentage of outgroup members in states and counties. As shown in Figure 4, explicit and implicit ingroup bias were highest among both White and Black respondents residing in states and counties with outgroup proportions approaching 50:50 and lowest when outgroup proportions were near the extremes. ${ }^{7}$

Importantly, ingroup bias may also mean something quite different for members of a dominant majority-group versus an oppressed minority-group. For White U.S. residents, ingroup bias represents attitudes consistent with structural racism, whereas for Black U.S. residents ingroup bias may, among other things, represent negative attitudes toward their oppressors, resistance to systemic racism, or pride in the ingroup's ability to persevere and overcome obstacles. Considering these different meanings, the weaker ingroup biases among Black

\footnotetext{
${ }^{7}$ Figure 4 was produced to help interpret the seemingly contradictory results we observed in Tables 2-4. Rather than formally testing hypotheses generated by the data in the present samples, our 50:50 hypothesis should be tested in a confirmation sample.
} 
respondents living in predominantly White communities may reflect internalized racism among individuals surrounded by outgroup members in a society structured to favor that outgroup (Watts-Jones, 2002). In contrast, for dominant majority-group members, larger proportions of outgroup members may signal a threat to the status quo, stoking fears that White mainstream culture will no longer be maintained (Craig \& Richeson, 2017). From a historical perspective, contemporary residential distributions of Black U.S. residents remain correlated with the proportion of enslaved Black people in 1860 (Payne et al., 2019). Thus, many U.S. regions that currently have large Black populations (particularly in the Southeast) also have strong historical ties to slavery and the Confederacy, and many still have monuments glorifying this time of extreme racial oppression (O'Connell, 2020). Such historical factors likely contribute to the relation between outgroup proportions and intergroup biases observed in the U.S. 

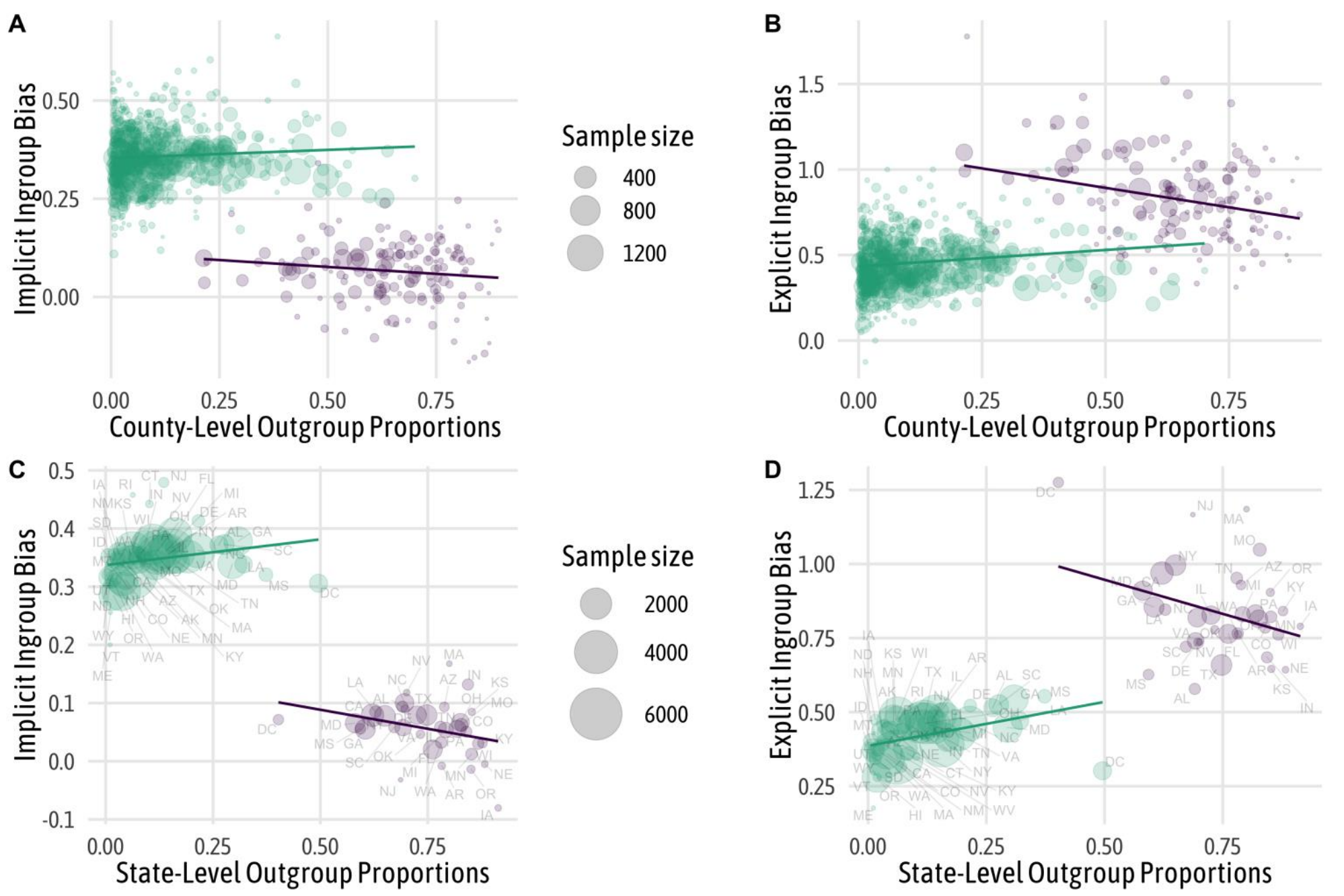

Figure 4. Outgroup proportions plotted against aggregated implicit (county-level: panel A; state-level: panel C) and explicit (countylevel: panel B; state-level: panel D) standardized ingroup bias scores for White and Black respondents. The size of each data point indicates the sample size. Only states and counties with at least 20 respondents are plotted. 
INTERGROUP CONTACT AND OUTGROUP PROPORTIONS

Interestingly, outgroup proportions predicted bias at different units of analysis. Oliver and Wong (2003) found that outgroup proportions predicted greater ingroup bias at larger geographical units, whereas at smaller geographical units they predicted lesser ingroup bias. This pattern may suggest that outgroup proportions in larger units may become centerpieces of political debate and thus cue economic or political threat (Blalock, 1967; Wagner et al., 2006), and that outgroup proportions likely have a stronger link with intergroup contact in smaller contextual units (see Figure 2). Along these lines, we found that greater outgroup proportions at smaller (county-level) units predicted reduced ingroup bias (among Black respondents), whereas outgroup proportions at larger (state-level) units predicted greater ingroup bias (among White respondents). The somewhat tighter correspondence between intergroup contact and county-level outgroup proportions, combined with the fact that larger outgroup proportions predicted lower ingroup bias among Black respondents, may explain why we did not observe interactions between intergroup contact and outgroup proportions for Black respondents. Our finding that the association between outgroup proportions and explicit racial bias was constrained to the state level for White respondents and county level for Black respondents was unanticipated, but replicated; hence, future research should continue to explore various units of analysis to better understand relations among outgroup proportions, intergroup contact, and ingroup bias.

We also observed unexpected findings regarding implicit bias, such that outgroup proportions at neither state nor county levels robustly predicted implicit ingroup bias (but did predict explicit ingroup bias). One parsimonious explanation for these null relationships is measurement error. Whereas the IAT tends to have the strongest psychometric qualities among implicit measures (Bar-Anan \& Nosek, 2014), all implicit measures (including the IAT) are plagued by high levels of measurement error (Cunningham, Preacher, \& Banaji, 2001), which 
explains attenuated relations between implicit ingroup bias scores and criterion variables (Furr \& Bacharach, 2013). Similarly, our finding that outgroup proportions did not reliably predict respondents' individual-level implicit ingroup bias may seem surprising given Rae et al.'s (2015) observation that outgroup proportions predicted Black respondents' implicit ingroup bias scores when aggregated at the state and county levels. However, aggregation of noisy individual-level measurements can result in accurate measures of group means (Connor \& Evers, 2020), explaining the discrepancy between our results and those of Rae et al. (2015).

Notwithstanding these contributions, we acknowledge key limitations. First, our analyses were correlational, preventing causal conclusions. Second, our measure of explicit bias was limited to one item and the measure of intergroup contact was limited to the number of types (e.g., childhood friend, teacher, romantic partner) of former and current close relationships with outgroup members. Although single-item measures have limitations, the one we employed represents a particularly high-quality index of explicit racial bias (Axt, 2018). Future work should, however, assess distinct aspects of contact that may predict explicit and implicit bias (e.g., quality and quantity of contact; Turner et al., 2007), as well as whether different types of close relationships (e.g., childhood vs. adult friendships) are differentially associated with ingroup bias. Lastly, our results may be group-specific (i.e., Black/White relations) and contextspecific (i.e., to the U.S.). Future research assessing bias toward different groups and measuring outgroup proportions across even smaller units (e.g., neighborhoods; see Devos et al., 2021) or as they change over time might yield different findings.

In conclusion, we qualify previous claims that larger outgroup proportions necessarily predict greater ingroup bias. By focusing on reactions to larger outgroup proportions among dominant majority-group members, prior work may have overlooked how greater outgroup 
proportions can predict lower ingroup bias among oppressed minority-group members. Moreover, although larger outgroup proportions may increase dominant majority-group members' ingroup bias, intergroup contact can mitigate this negative outcome. 


\section{References}

Allport, G. W. (1954). The nature of prejudice. Reading, MA: Addison-Wesley.

Axt, J. R. (2018). The best way to measure explicit racial attitudes is to ask about them. Social Psychological and Personality Science, 9, 896-906. doi: 10.1177/1948550617728995

Bar-Anan, Y., \& Nosek, B. A. (2014). A comparative investigation of seven indirect attitude measures. Behavior Research Methods, 46, 668-688. doi: 10.3758/s13428-013-0410-6

Barlow, F. K., Hornsey, M J., Thai, M., Sengupta, N. K., \& Sibley, C. G. (2013). The wallpaper effect: The contact hypothesis fails for minority group members who live in areas with a high proportion of majority group members. PLoS ONE, 8, e8228. doi: 10.1371/journal.pone.0082228

Bates, D., Maechler, M., Bolker, B., \& Walker, S. (2015). lme4: Linear mixed-effects models using Eigen and S4 (R package version1.1-9). Retrieved from https://CRAN.Rproject.org/package $=$ lme 4

Bauer, D. J., \& Curran, P. J. (2005). Probing interactions in fixed and multilevel regression: Inferential and graphical techniques. Multivariate Behavioral Research, 40, 373-400. doi: 10.1207/s15327906mbr4003_5

Binder, J., Zagefka, H., Brown, R., Funke, F., Kessler, T., Mummendey, A., Maquil, A., Demoulin, S., \& Leyens, J.-P. (2009). Does contact reduce prejudice or does prejudice reduce contact? A longitudinal test of the contact hypothesis amongst majority and minority groups in three European countries. Journal of Personality and Social Psychology, 96, 843-856. doi: 10.1037/a0013470

Blalock, H. M. (1967). Toward a theory of minority-group relations. New York: Capricorn Books. 
Brincks, A. M., Enders, C. K., Llabre, M. M., Bulotsky-Shearer, R. J., Prado, G., \& Feaster, D. J. (2017). Centering predictor variables in three-level contextual models. Multivariate Behavioral Research, 52, 149-163. doi: 10.1080/00273171.2016.1256753

Brown, R., \& Hewstone, M. (2005). An integrative theory of intergroup contact. Advances in Experimental Social Psychology, 37, 255-343. doi: 10.1016/S0065-2601(05)37005-5

Christ, O., Schmid, K., Lolliot, S., Swart, H., Stolle, D., Tausch, N., Al Ramiah, A., Wagner, U., Vertovec, S., \& Hewstone, M. (2014). Contextual effect of positive intergroup contact on outgroup prejudice. Proceedings of the National Academy of Sciences, 111, 3996-4000. doi: 10.1073/pnas.1320901111

Cohen, P., Cohen, J., Aiken, L. S., \& West, S. G. (1999). The problem of units and the circumstance for POMP. Multivariate Behavioral Research, 34, 315-346. doi: 10.1207/S15327906MBR3403_2

Craig, M. A., \& Richeson, J. A. (2014). More diverse yet less tolerant? How the increasingly diverse racial landscape affects White Americans' racial attitudes. Personality and Social Psychology Bulletin, 40, 750-761. doi: 10.1177/0146167214524993

Craig, M. A., \& Richeson, J. A. (2017). Information about the US racial demographic shift triggers concerns about anti-White discrimination among the prospective White “minority”. PloS one, 12(9), e0185389. doi: 10.1371/journal.pone.0185389

Danbold, F., \& Huo, Y. J. (2015). No longer 'all-American'? Whites' defensive reactions to their numerical decline. Social Psychological and Personality Science, 6, 210-218. doi: $10.1177 / 1948550614546355$

DeHaven, A. (2017, May 23). Preregistration: A plan, not a prison [blog post]. Retrieved from https://cos.io/blog/preregistration-plan-not-prison/ 
Devos, T., Sadler, M., Perry, D., \& Yogeeswaran, K. (2021). Temporal fluctuations in context ethnic diversity over three decades predict implicit national inclusion of Asian Americans. Group Processes and Intergroup Relations, 24, 3-25. doi:

$10.1177 / 1368430219887440$

Dhont, K., \& Van Hiel, A. (2012). Intergroup contact buffers against the intergenerational transmission of authoritarianism and racial prejudice. Journal of Research in Personality, 46, 231-234. doi: 10.1016/j.jrp.2011.12.008

Enders, C. K., \& Tofighi, D. (2007). Centering predictor variables in cross-sectional multilevel models: A new look at an old issue. Psychological Methods, 12, 121-138. doi: 10.1037/1082-989X.12.2.121

Fossett, M. A., \& Kiecolt, K. J. (1989). The relative size of minority populations and white racial attitudes. Social Science Quarterly, 70, 820-835.

Gaertner, S. L., Dovidio, J. F., Guerra, R., Hehman, E., \& Saguy, T. (2016). A common ingroup identity: A categorization-based approach for reducing intergroup bias. In T. Nelson (Ed.), Handbook of prejudice, discrimination, and stereotyping (2nd Ed., pp. 433-454). New York, NY: Psychology Press.

Gawronski, B., \& Bodenhausen, G. V. (2006). Associative and propositional processes in evaluation: An integrative review of implicit and explicit attitude change. Psychological Bulletin, 132, 692-731. doi: 1037/0033-2909.132.5.692

Greenwald, A. G., McGhee, D. E., \& Schwartz, J. L. K. (1998). Measuring individual differences in implicit cognition: The Implicit Association Test. Journal of Personality and Social Psychology, 74, 1464-1480. doi: 10.1037//0022-3514.74.6.1464 
Greenwald, A. G., Nosek, B. A., \& Banaji, M. R. (2003). Understanding and using the Implicit Association Test: I. An improved scoring algorithm. Journal of Personality and Social Psychology, 85, 197-216. doi: 10.1037/0022-3514.85.2.197

Greenwald, A. G., Poehlman, T. A., Uhlmann, E. L., \& Banaji, M. R. (2009). Understanding and using the Implicit Association Test: III. Meta-analysis of predictive validity. Journal of Personality and Social Psychology, 97, 17-41. doi: 10.1037/a0015575

Hehman, E., Flake, J. K., \& Calanchini, J. (2018). Disproportionate use of lethal force in policing is associated with regional racial biases of residents. Social Psychological and Personality Science, 9, 393-401. doi: 10.1177/1948550617711229

Heisig, J. P., \& Schaeffer, M. (2019). Why you should always include a random slope for the lower-level variable involved in a cross-level interaction. European Sociological Review, 35, 258-279. doi: 10.1093/esr/jcy053

Kendi, I. X. (2016). Stamped from the beginning: The definitive history of racist ideas in America. New York, NY: Nation Books.

Kurdi, B., Seitchik, A. E., Axt, J. R., Carroll, T. J., Karapetyan, A., Kaushik, N., Tomeszko, D., Greenwald, A. G., \& Banaji, M. R. (2019). Relationship between the Implicit Association Test and intergroup behavior: A meta-analysis. American Psychologist, 74, 569-586. doi: 10.1037/amp0000364

Kuznetsova, A., Brockhoff, P. B., \& Christensen, R. H. B. (2014). lmerTest: Tests in Linear Mixed Effects Models (R package version 2.0-20). Retrieved from http://CRAN.Rproject.org/package $=$ lmerTest 
Levin, S., van Laar, C., \& Sidanius, J. (2003). The effects of ingroup and outgroup friendships on ethnic attitudes in college: A longitudinal study. Group Processes and Intergroup Relations, 6, 76-92. doi: 10.1177/1368430203006001013

Longshore, D. (1982). School racial composition and white hostility: The problem of control in desegregated schools. Social Forces, 61, 73-78.

Maas, C. J., \& Hox, J. J. (2005). Sufficient sample sizes for multilevel modeling. Methodology: European Journal of Research Methods for the Behavioral and Social Sciences, 1, 8692. doi: $10.1027 / 1614-2241.1 .3 .86$

Mullen, B. (1991). Group composition, salience, and cognitive representations: The phenomenology of being in a group. Journal of Experimental Social Psychology, 27, 297-323. doi: 10.1016/0022-1031(91)90028-5

Nezlek, J. B. (2008). An introduction to multilevel modeling for social and personality psychology. Social and Personality Psychology Compass, 2, 842-860. doi: 10.1111/j.1751-9004.2007.00059.x

Nosek, B. A., Smyth, F. L., Hansen, J. J., Devos, T., Lindner, N. M., Ranganath, K. A., Smith, C. T., Olson, K. R., Chugh, D., Greenwald, A. G., \& Banaji, M. R. (2007). Pervasiveness and correlates of implicit attitudes and stereotypes. European Review of Social Psychology, 18, 36-88. doi: 10.1080/10463280701489053

Nosek, B. A., Smyth, F. L., Sriram, N., Lindner, N. M., Devos, T., Ayala, A., Bar-Anan, Y., Bergh, R., Cai, H., Gonsalkorale, K., Kesebir, S., Maliszewski, N., Neto, F., Olli, E., Park, J., Schnabel, K., Shiomura, K., Tulbure, B. T., Wiers, R. W., Somogyi, M., Akrami, N., Ekehammar, B., Vianello, M., Banaji, M. R., \& Greenwald, A. G. (2009). National differences in gender-science stereotypes predict national sex differences in science and 
math achievement. Proceedings of the National Academy of Sciences, 106, 10593-10597. doi: 10.1073/pnas.0809921106

O’Connell, H. A. (2020). Monuments outlive history: Confederate monuments, the legacy of slavery, and black-white inequality. Ethnic and Racial Studies, 43(3), 460-478. doi: $10.1080 / 01419870.2019 .1635259$

Oliver, J., \& Wong, J. (2003). Intergroup prejudice in multiethnic settings. American Journal of Political Science, 47, 567-582. doi: 10.1111/1540-5907.00040

Orchard, J., \& Price, J. (2017). County-level racial prejudice and the Black-White gap in infant health outcomes. Social Science \& Medicine, 181, 191-198. doi: 10.1016/j.socscimed.2017.03.036

Oswald, F. L., Mitchell, G., Blanton, H., Jaccard, J., \& Tetlock, P. E. (2013). Predicting ethnic and racial discrimination: A meta-analysis of IAT criterion studies. Journal of Personality and Social Psychology, 105, 171-192. doi: 10.1037/a0032734

Paolini, S., Harwood, J., Rubin, M., Husnu, S., Joyce, N., \& Hewstone, M. (2014). Positive and extensive intergroup contact in the past buffers against the disproportionate impact of negative contact in the present. European Journal of Social Psychology, 44, 548-562. doi: 10.1002/ejsp.2029

Payne, B. K., Vuletich, H. A., \& Brown-Iannuzzi, J. L. (2019). Historical roots of implicit bias in slavery. Proceedings of the National Academy of Sciences, 40506, 201818816. doi: 10.1073/pnas.1818816116

Pettigrew, T. F., \& Tropp, L. R. (2006). A meta-analytic test of intergroup contact theory. Journal of Personality and Social Psychology, 90, 751-783. doi: 10.1037/00223514.90 .5 .751 
Preacher, K. J., Curran, P. J., \& Bauer, D. J. (2006). Computational tools for probing interactions in multiple linear regression, multilevel modeling, and latent curve analysis. Journal of Educational and Behavioral Statistics, 31, 437-448. doi: 10.3102/10769986031004437

Project Implicit (n.d.). About us. Retrieved from http://www.projectimplicit.net/about.html

Putnam, R. D. (2007). E pluribus unum: Diversity and community in the twenty-first century: The 2006 Johan Skytte Prize Lecture. Scandinavian Political Studies, 30, 137-174. doi: 10.1111/j.1467-9477.2007.00176.x

Quillian, L. (1996). Group threat and regional change in attitudes toward AfricanAmericans. American Journal of Sociology, 102, 816-860. doi: 10.1086/230998

R Core Team. (2014). R: A language and environment for statistical computing. Vienna, Austria: R Foundation for Statistical Computing. Retrieved from http://www.Rproject.org/

Rae, J. R., Newheiser, A. K., \& Olson, K. R. (2015). Exposure to racial out-groups and implicit race bias in the United States. Social Psychological and Personality Science, 6, 535-543. doi: $10.1177 / 1948550614567357$

Raudenbusch, S. W., \& Bryk, A. S. (2002). Hierarchical linear models: Applications and data analysis methods (2nd Ed.). Thousand Oaks, CA: Sage.

Rydell, R. J., \& McConnell, A. R. (2006). Understanding implicit and explicit attitude change: A systems of reasoning analysis. Journal of Personality and Social Psychology, 91, 9951008. doi: 10.1037/0022-3514.91.6.995

Sadler, M., \& Devos, T. (2020). Ethnic diversity matters: Putting implicit associations between weapons and ethnicity in context. Group Processes and Intergroup Relations, 23, 285300. doi: $10.1177 / 1368430218796933$ 
Schmid, K., Al Ramiah, A., \& Hewstone, M. (2014). Neighborhood ethnic diversity and trust: The role of intergroup contact and perceived threat. Psychological Science, 25, 665-674. doi: $10.1177 / 0956797613508956$

Schmid, K., Wölfer, R., Swart, H., Christ, O., Al Ramiah, A., Vertovec, S., \& Hewstone, M. (2017). The 'Wallpaper effect' revisited: Divergent findings on the effects of intergroup contact on attitudes in diverse vs. non-diverse contexts. Personality and Social Psychology Bulletin, 43, 1268-1283. doi: 10.1177/0146167217711929

Shelton, J. N. (2000). A reconceptualization of how we study issues of racial prejudice. Personality and Social Psychology Review, 4, 374-390. doi: 10.1207/S15327957PSPR0404_6

Shook, N. J., \& Fazio, R. H. (2008). Interracial roommate relationships: An experimental field test of the contact hypothesis. Psychological Science, 19, 717-723. doi: 10.1111/j.14679280.2008.02147.x

Snijders, T. A. B. (2005). Power and sample size in multilevel modeling. In B. S. Everitt \& D. C. Howell (Eds.), Encyclopedia of statistics in behavioral science (Vol. 3, pp. 1570-1573). Chichester, England: Wiley.

Stein, R. M., Post, S. S., \& Rinden, A. L. (2000). Reconciling context and contact effects on racial attitudes. Political Research Quarterly, 53, 285-303. doi: $10.1177 / 106591290005300204$

Taylor, M. C. (1998). How White attitudes vary with the racial composition of local populations: Numbers count. American Sociological Review, 63, 512-535. doi: 10.2307/2657265 
Tropp, L. R. \& Pettigrew, T. F. (2005). Differential relationships between intergroup contact and affective and cognitive dimensions of prejudice. Personality and Social Psychology Bulletin, 31(8):1145-1158. doi: 10.1177/0146167205274854

Turner, R. N., Hewstone, M., \& Voci, A. (2007). Reducing explicit and implicit outgroup prejudice via direct and extended contact: The mediating role of self-disclosure and intergroup anxiety. Journal of Personality and Social Psychology, 93, 369-388. doi: $10.1037 / 0022-3514.93 .3 .369$

Wagner, U., Christ, O., Pettigrew, T. F., Stellmacher, J., \& Wolf, C. (2006). Prejudice and minority proportion: Contact instead of threat effects. Social Psychology Quarterly, 69, 380-390. doi: 10.1177/019027250606900406

Watts-Jones, D. (2002). Healing internalized racism: The role of a within-group sanctuary among people of African descent. Family Process, 41, 591-601. doi: 10.1111/j.1545$5300.2002 .00591 . x$

Xu, K., Nosek, B., \& Greenwald, A. (2014). Psychology data from the race Implicit Association Test (IAT) on the Project Implicit demo website. Journal of Open Psychology Data, 2. doi: 10.5334/jopd.ac 